\title{
Metal-Metal Bonding Properties of Copper Oxide Nanoparticles*
}

\author{
Takafumi Maeda ${ }^{\dagger}$ and Yoshio Kobayashi \\ Department of Biomolecular Functional Engineering, College of Engineering, \\ Ibaraki University, 4-12-1 Naka-narusawa-cho, Hitachi, Ibaraki 316-8511, Japan \\ Yusuke Yasuda and Toshiaki Morita \\ Hitachi Research Laboratory, Hitachi Ltd., 7-1-1 Omika-cho, Hitachi, Ibaraki 319-1292, Japan
}

(Received 5 December 2013; Accepted 31 January 2014; Published 8 March 2014)

\begin{abstract}
The present study performs production of copper oxide particles, and examines the particles as a filler in metalmetal bonding. Leaf-like aggregates with a longitudinal size of ca. $600-950 \mathrm{~nm}$ and a lateral size of ca. $280-380 \mathrm{~nm}$, which were composed of particles with a size of ca. $10 \mathrm{~nm}$, were produced with a salt-base reaction using a $\mathrm{Cu}\left(\mathrm{NO}_{3}\right)_{2}$ aqueous solution and an $\mathrm{NaOH}$ aqueous solution. Copper discs were bonded by pressurizing them, between which the particles were sandwiched, at $1.2 \mathrm{MPa}$ for $5 \mathrm{~min}$ in $\mathrm{H}_{2}$ gas under annealing at $400^{\circ} \mathrm{C}$. Bonding properties of particles were evaluated by measuring shear strength, which was required to separate the discs. The shear strengths were as large as ca. $23 \mathrm{MPa}$ at $\mathrm{NaOH} / \mathrm{Cu}\left(\mathrm{NO}_{3}\right)_{2}$ ratios of 1.9 and 2.0, since $\mathrm{CuO}$ particles that contained nether $\mathrm{Cu}_{2}(\mathrm{OH})_{3} \mathrm{NO}_{3}$ nor impurity based on the addition of $\mathrm{NaOH}$ were produced at the ratios.
\end{abstract}

[DOI: 10.1380/ejssnt.2014.105]

Keywords: Copper oxide; Metal-metal bonding; Nanoparticle

\section{INTRODUCTION}

The lead-tin alloys are common as fillers or solders for metal-metal bonding, since they have low melting points $[1,2]$. The low melting point is a useful property in metal-metal bonding, because metallic materials can be bonded using the alloys at low temperature. The use of lead is showing a tendency to be limited because of its toxicity for living bodies [3]. Accordingly, various lead-free tin-based alloys have been developed as new solders [4-7]. The tin-based alloys still have a problem on their low melting point. The bonded materials may be released at temperatures higher than a melting point of the alloys due to their remelting. The electrical devices are required to be miniaturized, and to act with high power. Consequently, heat is evolved, which exposes the electrical devises at high temperature, and may remelt the alloys in bonded sites.

Nanoparticles of metals have advantage for metal-metal bonding [8-12]. Metal-metal bonding is typically implemented by applying both pressure and temperature to the materials to be bonded, which promotes diffusion of metals into the materials [13-15]. A decrease in a size of material to nanometer order provides a depression of its melting point [16, 17]. The depression can be applied to metal-metal bonding at low temperature, which has been performed by several researchers [8-12]. The use of metallic nanoparticles has another advantage for metal-metal bonding. The bonded materials are expected not to be released at the bonding temperature, because the nanoparticles become bulk with higher melting points during the bonding. This expectation may solve the problem on remelting.

\footnotetext{
${ }^{*}$ This paper was presented at the 12 th International Conference on Atomically Controlled Surfaces, Interfaces and Nanostructures (ACSIN-12) in conjunction with the 21st International Colloquium on Scanning Probe Microscopy (ICSPM21), Tsukuba International Congress Center, Tsukuba, Japan, November 4-8, 2013.

${ }^{\dagger}$ Corresponding author: 12nd110n@hcs.ibaraki.ac.jp
}

Among various metals, metallic $\mathrm{Cu}$ is promising as the filler; It is available at low cost, and has high electro-conductivity and non-ionic migration property. Its nanoparticles tend to be oxidized in air, which deteriorates its bonding ability. Since $\mathrm{CuO}$ is easily reduced to metallic $\mathrm{Cu}$ in reducing atmosphere, metal-metal bonding through the reduction may be attained simultaneously by using the $\mathrm{CuO}$ particles as the filler. Our research group has previously developed a method for fabricating $\mathrm{CuO}$ nanoparticles $[18,19]$. The $\mathrm{CuO}$ nanoparticle colloid solutions were prepared by reacting $\mathrm{Cu}\left(\mathrm{NO}_{3}\right)_{2}$ with $\mathrm{NaOH}$ in aqueous solution. Morphology such as shape and size of the particles was dependent on concentrations of chemicals or a $\mathrm{NaOH} / \mathrm{Cu}\left(\mathrm{NO}_{3}\right)_{2}(\mathrm{Na} / \mathrm{Cu})$ ratio. The morphology will give effect on bonding ability. The present work examines $\mathrm{CuO}$ nanoparticles fabricated at various $\mathrm{Na} / \mathrm{Cu}$ ratios for their bonding abilities.

\section{EXPERIMENTAL}

\section{A. Chemicals}

Copper (II) nitrate trihydrate $\left(\mathrm{Cu}\left(\mathrm{NO}_{3}\right)_{2} \cdot 3 \mathrm{H}_{2} \mathrm{O}\right)(77.0-$ $80.0 \%$ (as $\left.\mathrm{Cu}\left(\mathrm{NO}_{3}\right)_{2}\right)$ ) was used as starting materials for producing $\mathrm{CuO}$ nanoparticles. Sodium hydroxide solution $(\mathrm{NaOH})(5 \mathrm{M})$ was used as base acting on $\mathrm{Cu}^{2+}$ ions. All the chemicals were purchased from Kanto Chemical Co., Inc., and used as received. Water that was ion-exchanged and distilled with Yamato WG-250 was used in all the preparations.

\section{B. Preparation}

Colloid solutions of $\mathrm{CuO}$ nanoparticles were synthesized through salt-base reaction. An aqueous solution of $\mathrm{NaOH}$ was added to a $\mathrm{Cu}\left(\mathrm{NO}_{3}\right)_{2}$ aqueous solution under vigorous stirring. The reaction temperature was $20^{\circ} \mathrm{C}$. Initial concentrations of $\mathrm{Cu}\left(\mathrm{NO}_{3}\right)_{2}$ and $\mathrm{NaOH}$ were 0.01 and 0.015-0.021 $\mathrm{M}$ in the final solution, respectively, which 


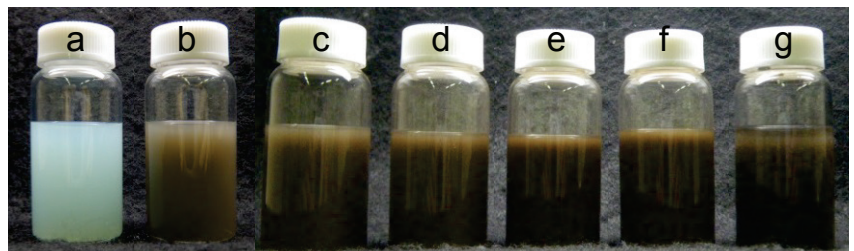

FIG. 1: Photographs of particle colloid solutions prepared at $\mathrm{Na} / \mathrm{Cu}$ ratios of (a) 1.5, (b) 1.6, (c) 1.7, (d) 1.8 , (e) 1.9, (f) 2.0 , and $(\mathrm{g}) 2.1$.

resulted in $\mathrm{Na} / \mathrm{Cu}$ molar ratios of 1.5-2.1. The reaction times were $24 \mathrm{~h}$.

\section{Characterization}

The $\mathrm{CuO}$ particles were characterized by transmission electron microscopy (TEM) and X-ray diffractometry (XRD). TEM photographs were taken with a JEOL JEM2100 microscope operating at $200 \mathrm{kV}$. Samples for TEM were prepared by dropping and evaporating the particle colloid on a collodion-coated copper grid. Dozens of particle diameters in TEM images were measured to determine number-averaged particle size and standard deviation of particle size distribution. XRD measurements were carried out with a Rigaku Ultima IV X-ray diffractometer operating at $40 \mathrm{kV}$ and $30 \mathrm{~mA}$ with $\mathrm{CuK} \alpha$ radiation. For preparing the powder sample for the XRD measurement, supernatant of the particle colloid solution was removed with decantation, and then residue was dried at room temperature for $24 \mathrm{~h}$ in vacuum. Metal-metal bonding property was investigated by the same set-up as used in our previous works $[8,18,19]$. Powder samples were sandwiched between copper discs (a stage (diameter: $10 \mathrm{~mm}$, thickness: $5 \mathrm{~mm}$ ) and a plate (diameter: $5 \mathrm{~mm}$, thickness: $2.5 \mathrm{~mm})$ ), and pressed at 1.2 MPa under annealing in $\mathrm{H}_{2}$ at $400^{\circ} \mathrm{C}$ for $5 \mathrm{~min}$ with a Shinko Seiki vacuum reflow system. For measurements of bonding strength, shear strengths, which were required to separate the bonded plate and stage, were measured with a Seishin SS-100KP bond tester. The copper plate was observed with a JEOL JSM-5600LV microscope after the measurements of shear strengths.

\section{RESULTS AND DISCUSSION}

\section{A. Morphology of particles}

Figure 1 shows photographs of the nanoparticle colloid solutions prepared at various $\mathrm{Na} / \mathrm{Cu}$ ratios. The colloid solutions were bluish and opaque at a ratio of 1.5 , brownish at 1.6-2.0, and grayish black at 2.1. The observations implied that a large amount of $\mathrm{CuO}$, which has a color of black, was produced at the large $\mathrm{Na} / \mathrm{Cu}$ ratio. At 2.1, the colloid solution with the color of grayish black was not highly dispersed, and sedimentation of particles took place immediately after preparation.

Figure 2 shows TEM images of various particles. At the

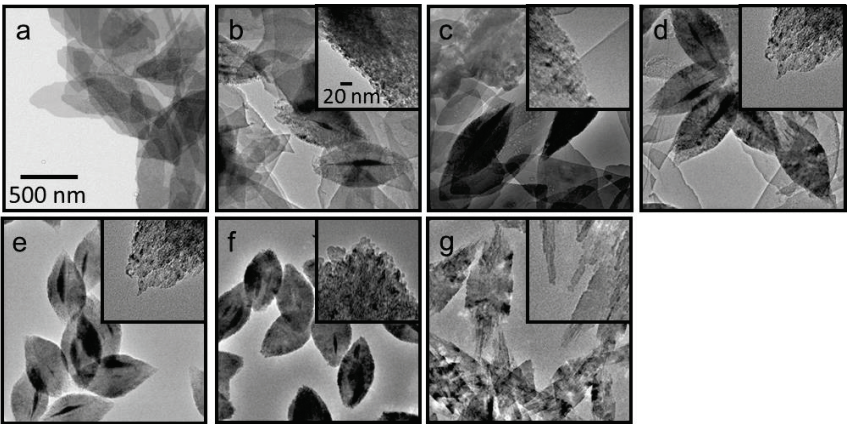

FIG. 2: TEM images of various particles. The samples were the particles contained in the same colloid solutions as in Fig. 1.

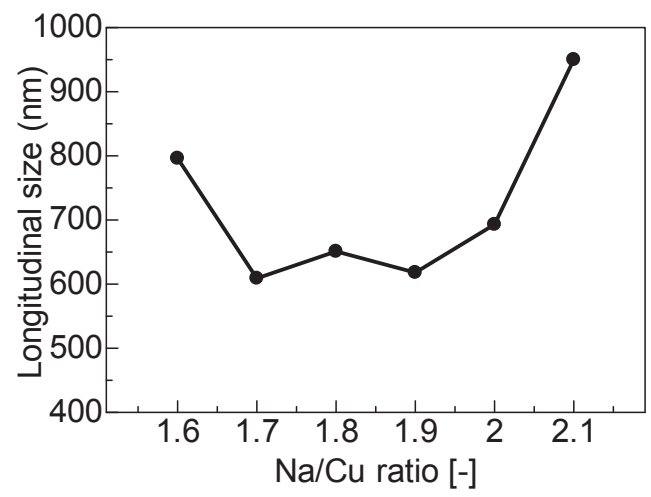

FIG. 3: Plot of the longitudinal size versus the $\mathrm{Na} / \mathrm{Cu}$ ratios.

ratio of 1.5 , objects like thin plates were observed, which might have been related to the production of bluish and opaque colloid solution. At 1.6, leaf-like aggregates were produced besides the plate-like particles. At 1.7-2.1, the plate-like particles disappeared, and only the leaf-like aggregates were observed. Their high magnification imaging revealed that the aggregates were composed of nanoparticles with a size of ca. $10 \mathrm{~nm}$. Since the lateral size of aggregates were almost constant at ca. $300 \mathrm{~nm}$ at 1.6-2.1, their longitudinal size was regarded as the aggregate size in the present work. Figure 3 shows a plot of the longitudinal size versus the $\mathrm{Na} / \mathrm{Cu}$ ratio. In the range of 1.6-2.0, the longitudinal size tended to decrease from 796 to $601 \mathrm{~nm}$ with the increase in the ratio. At $\mathrm{Na} / \mathrm{Cu}$ ratios smaller than the stoichiometric ratio of 2.0, ionic strength of the solution probably decreased, because $\mathrm{Cu}^{2+}$ ions and $\mathrm{OH}^{-}$ions derived from $\mathrm{NaOH}$ added were consumed for producting $\mathrm{Cu}(\mathrm{OH})_{2}$ particles. Thickness of electrical double layer around particles increases as ionic strength decreases $[20,21]$. The increase in electrical double layer thickness provided prevention of particle collision following aggregation of the particles. As a result, the aggregate size decreased with the increase in $\mathrm{Na} / \mathrm{Cu}$ ratio. The increase in ratio to 2.1 provided an increase in longitudinal size to $950 \mathrm{~nm}$. Addition of $\mathrm{NaOH}$ was considered to increase the amounts of $\mathrm{Na}^{+}$ions and $\mathrm{OH}^{-}$ions in the solution. The increase in $\mathrm{Na} / \mathrm{Cu}$ ratio resulted in an increase in ionic strength of the solution in a range of ratio larger than the stoichiometric ratio of 2.0. An increase 


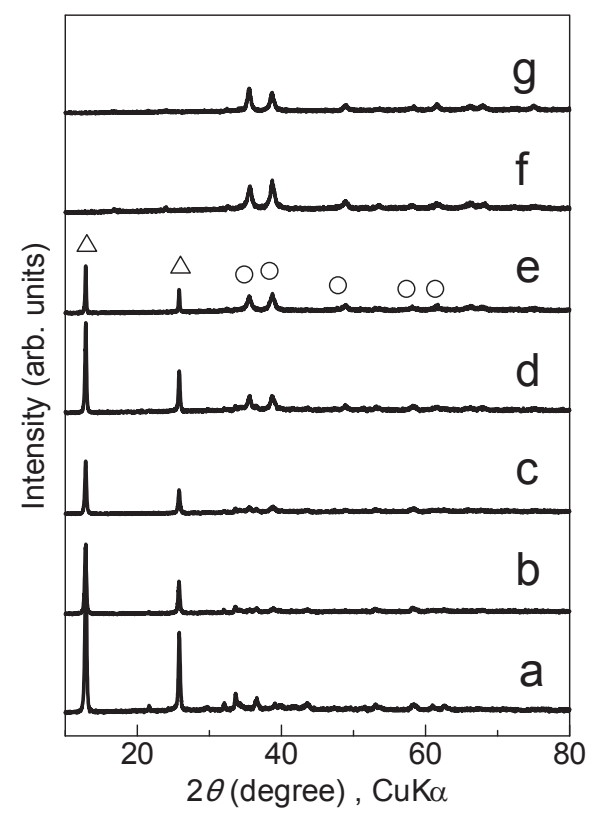

FIG. 4: XRD pattern of various particles. The samples were the particles contained in the same colloid solutions as in Fig. 1. $\bigcirc: \mathrm{CuO}, \triangle: \mathrm{Cu}_{2}(\mathrm{OH})_{3} \mathrm{NO}_{3}$.

in ionic strength reduces thickness of electrical double layer around particles $[20,21]$, in contrary to the case of above-stated decrease in ionic strength. Accordingly, the increase in ionic strength made the $\mathrm{CuO}$ particles approach to other $\mathrm{CuO}$ particles because of the decrease in thickness of electrical double layer around particles, which promoted aggregation of particles in the present work. As a result, the aggregate size increased with the increase in $\mathrm{Na} / \mathrm{Cu}$ ratio.

Figure 4 shows XRD patterns of various particles. At the ratios of 1.5 and 1.6, peaks were detected at 12.8 and 25.8 degree, which were attributed to copper nitrate hydroxide $\left(\mathrm{Cu}_{2}(\mathrm{OH})_{3} \mathrm{NO}_{3}\right)$ (JCPDS card NO. 150014). At 1.7 and 1.9 , besides the $\mathrm{Cu}_{2}(\mathrm{OH})_{3} \mathrm{NO}_{3}$ peaks, peaks attributed to $\mathrm{CuO}$ (JCPDS card NO. 05-0661) were recorded at 35.6, 38.8, and 48.9 degree. It was found that transformation from $\mathrm{Cu}_{2}(\mathrm{OH})_{3} \mathrm{NO}_{3}$ to $\mathrm{CuO}$ took place with increasing the $\mathrm{Na} / \mathrm{Cu}$ ratio. Only the peaks attributed to $\mathrm{CuO}$ were detected at 2.0 and 2.1. Possibly, the transformation reaction was completed at the high ratios. Average crystal sizes were estimated from the XRD line broadening of the 35.6 peak according to the Scherrer equation; they were $11.4,13.5,15.8,15.8$, and $17.6 \mathrm{~nm}$ for the ratios of $1.7,1.8,1.9,2.0$ and 2.1 , respectively. The crystal sizes roughly corresponded to the particle size of ca. $10 \mathrm{~nm}$ that composed the aggregates. This indicated that the particles were single crystals.

\section{B. Bonding properties}

The discs could be bonded for the all the samples examined. Figure 5 shows photographs of $\mathrm{Cu}$ discs after measurement of shear strength. All the discs had reddish brown products on their surfaces, which appeared to be metallic $\mathrm{Cu}$. Since it is hard to distinguish XRD peaks of
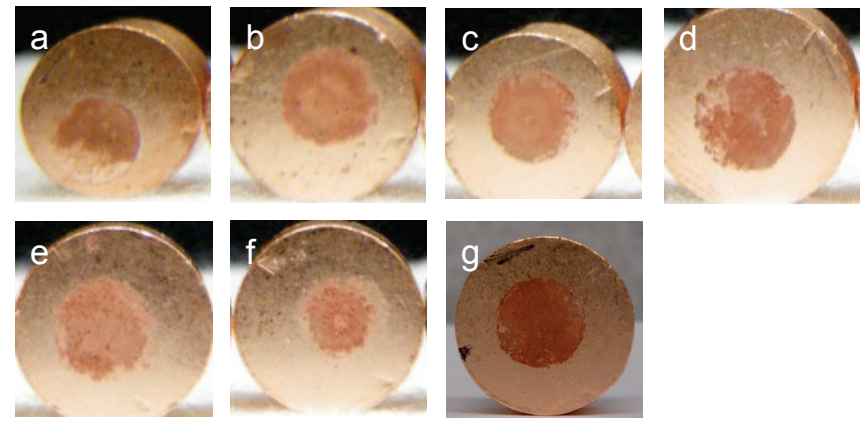

FIG. 5: Photographs of copper discs after measurements of shear strength. The samples used as fillers for bonding were the particles contained in the same colloid solutions as in Fig. 1.

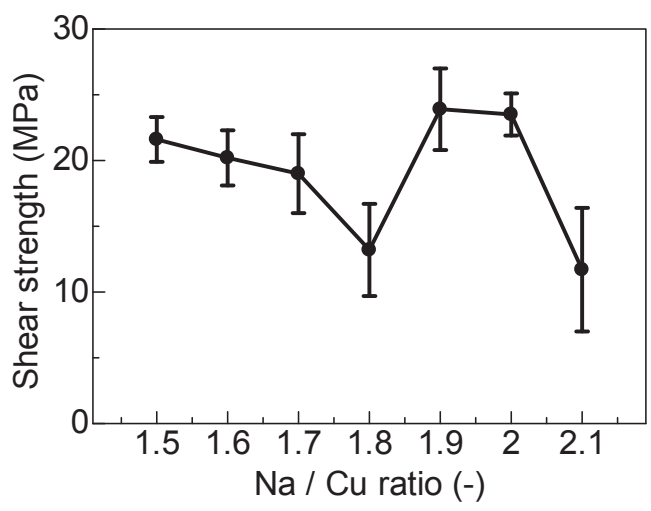

FIG. 6: Shear strength as a function of $\mathrm{Na} / \mathrm{Cu}$ ratio.

the $\mathrm{Cu}$-based particles from the $\mathrm{Cu}$ disc, the particles on $\mathrm{Cu}$ discs after the measurements of shear strength were not characterized by the XRD in the present work. Our previous work that performed XRD measurement for particles on an aluminum disc after bonding with the use of $\mathrm{CuO}$ nanoparticles at $400^{\circ} \mathrm{C}$ in $\mathrm{H}_{2}$ gas and measurement of shear strength reported complete reduction of $\mathrm{CuO}$ to metallic $\mathrm{Cu}$ [19]. Possibly, the reduction of $\mathrm{CuO}$ to metallic $\mathrm{Cu}$ also took place between the $\mathrm{Cu}$ discs in the present work. Thus, the annealing at $400^{\circ} \mathrm{C}$ in $\mathrm{H}_{2}$ gas reduced the particles to metallic $\mathrm{Cu}$, resulted in the bonding of discs.

Figure 6 summarizes results of measurements of shear strengths. The shear strengths were 21.6, 20.2, 19.0, 13.2, $23.9,23.4$ and $11.7 \mathrm{MPa}$ for the $\mathrm{Na} / \mathrm{Cu}$ ratios of $1.5,1.6$, $1.7,1.8,1.9,2.0$ and 2.1 , respectively; The large shear strengths were recorded at 1.9 and 2.0. According to previous work performing thermal analysis of particles containing $\mathrm{Cu}_{2}(\mathrm{OH})_{3} \mathrm{NO}_{3}$ [19], nitrate and water were eliminated out of $\mathrm{Cu}_{2}(\mathrm{OH})_{3} \mathrm{NO}_{3}$ and then transformed $\mathrm{CuO}$ at ca. $200^{\circ} \mathrm{C}$. In the present work, the elimination shrank the particles, and then voids, i.e., gaps were produced among the particles in the bonded parts composed of the particles. The bonded parts became sparse with the production of voids. This probably provided weak bonding; The small shear strengths were recorded at the $\mathrm{Na} / \mathrm{Cu}$ ratios as small as 1.5-1.7, at which many $\mathrm{Cu}_{2}(\mathrm{OH})_{3} \mathrm{NO}_{3}$ were contained in the particles. At the ratio of 2.1, a large 

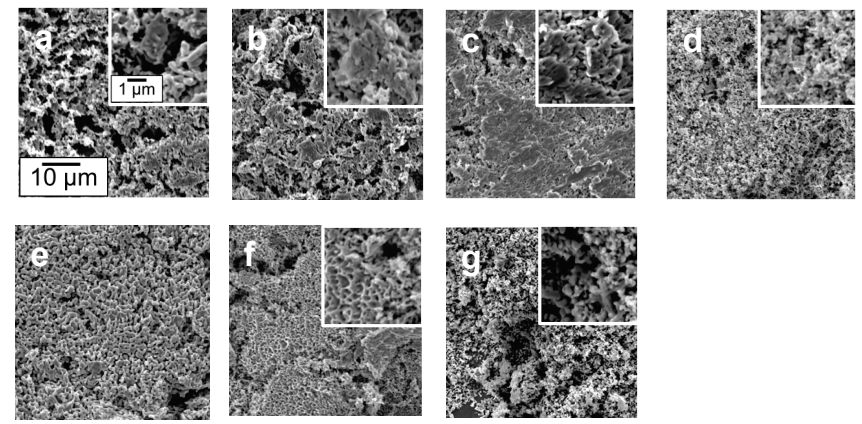

FIG. 7: SEM images of copper discs after measurements of shear strength. The samples used as fillers for bonding were the particles contained in the same colloid solutions as in Fig. 1.

amount of $\mathrm{NaOH}$ was added to the solution, compared to other small ratios. Thus, the $\mathrm{CuO}$ particles should have contained a lot of $\mathrm{Na}^{+}$ions as impurity. This might have provided an increase in the impurity contained in the particles, which spoiled the bonding.

Figure 7 shows SEM images of copper disc surfaces after the measurement of shear strength. The voids that were considered to be produced among the particles were too small to observe them by the SEM. Many dimples were observed accompanying with sharp tip on the surface at the ratios of 1.9 and 2.0, and the amounts of such dimples were not large in other ratios. Dimples are formed in bonded sites when metals are strongly bonded [8, 18, 19]. Accordingly, the SEM observations for the dimples supported the strong bonding at 1.9 and 2.0.

[1] L. Li, and W. H. Muller, Comp. Mater. Sci. 21, 159 (2001).

[2] Y. F. Chiu, Y. L. Tsai, and W. S. Hwang, Appl. Math. Model. 27, 565 (2003).

[3] D. Li, P. P. Conway, and C. Liu, Corros. Sci. 50, 995 (2008).

[4] A. A. El-Daly, and A. M. El-Taher, Mater. Des. 51, 789 (2013).

[5] H. Fallahi, M. S. Nurulakmal, A. F. Arezodar, and J. Adbullah, Mater. Sci. Eng. 553, 22 (2012).

[6] V. L. Niranjani, B. S. S. C. Rao, R. Sarkar, and S. V. Kamat, J. Alloys. Compd. 542, 136 (2012).

[7] M. A. A. M. Salleh, A. M. M. A. Bakri, H. Kamarudin, M. Bnhussain, M. H. Zan@Hazizi, and F. Somidin, Phys. Procedia 22, 299 (2011).

[8] T. Maeda, Y. Abe, Y. Kobayashi, Y. Yasuda, and T. Morita, Sci. Technol. Weld. Join. 17, 489 (2012).

[9] H. Nishikawa, T. Hirano, and T. Takemoto, Trans. JWRI 40, 33 (2011).

[10] Y. Yasuda, E. Ide, and T. Morita, Jpn. J. Appl. Phys. 48, 125004 (2009).

[11] H. Alarifi, A. Hu, M. Yavuz, and Y. N. Zhou, J. Electron

\section{CONCLUSIONS}

The leaf-like aggregates with the longitudinal size of ca. $600-950 \mathrm{~nm}$ and the lateral size of ca. $280-380 \mathrm{~nm}$, which were composed of nanoparticles with the size of ca. $10 \mathrm{~nm}$ were produced by the reaction between $\mathrm{Cu}\left(\mathrm{NO}_{3}\right)_{2}$ and $\mathrm{NaOH}$. The aggregate size was dependent on the $\mathrm{Na} / \mathrm{Cu}$ ratio related to ionic strength of the solution. According to XRD, the $\mathrm{Cu}_{2}(\mathrm{OH})_{3} \mathrm{NO}_{3}$, the mixture of $\mathrm{CuO}$ and $\mathrm{Cu}_{2}(\mathrm{OH})_{3} \mathrm{NO}_{3}$ and the $\mathrm{CuO}$ were produced at the ratios of $1.7,1.8$ and 1.9 , respectively. The bonding examinations, which were performed by pressurizing the particles sandwiched between the copper discs at 1.2 $\mathrm{MPa}$ for $5 \mathrm{~min}$ in $\mathrm{H}_{2}$ gas at $400^{\circ} \mathrm{C}$ and then measuring the shear strength required for separating the discs, revealed that the shear strengths as large as 23.9 and $23.4 \mathrm{MPa}$ were recorded at 1.9 and 2.0, respectively. The mechanisms for these results could be explained with the elimination of nitrate and water from the aggregates at the small ratios and the presence of the large amount of impurity contained in the aggregates at the large ratio.

\section{Acknowledgments}

This work was partially supported by Hitachi, Ltd. We express our thanks to Prof. T. Noguchi in College of Science of Ibaraki University, Japan for their help for TEM observation.
Mater. 40, 1394 (2011).

[12] S. Wang, H. Ji, M. Li, and C. Wang, Mater. Lett. 85, 61 (2012).

[13] X. Yuan, K. Tang, Y. Deng, J. Luo, and G. Sheng, Mater. Des. 52, 359 (2013).

[14] T. Iamboliev, S. Valkanov, and S. Atanasova, Int. J. Refract. Met. Hard Mater. 37, 90 (2013).

[15] K. Aydin, Y. Kaya, and N. Kahraman, Mater. Des. 37, 356 (2012).

[16] J. Lee, J. Park, and T. Tanaka, Calphad 33, 377 (2009).

[17] M. S. Omar, Mater. Res. Bull. 47, 3518 (2012).

[18] T. Maeda, Y. Kobayashi, Y. Yasuda, and T. Morita, Sci. Technol. Weld. Join. 17, 556 (2012).

[19] Y. Kobayashi, T. Maeda, K. Watanabe, K. Ihara, Y. Yasuda, and T. Morita, J. Nanoparticle Res. 13, 5365 (2011).

[20] C. H. Bolster, A. L. Mils, G. M. Hornberger, and J. S. Herman, J. Contam. Hydrol. 50, 287 (2001).

[21] B. Gilbert, R. K. Ono, K. A. Ching, and C. S. Kim, J. Colloid Interface Sci. 339, 285 (2009). 